\title{
Economia mineral e os impactos nos territórios amazônicos do sudeste paraense
}

\author{
Mineral economy and impacts in the amazonian territories of southeast paraense
}

\author{
João Marcio Palheta da Silva ${ }^{1}$ e Ricardo Ângelo Pereira de Lima ${ }^{21}$ \\ 1 Professor Associado III/Universidade Federal do Pará/Coordenador do Programa de Pós-Graduação em Geografia da UFPA/Líder do \\ Grupo Acadêmico Produção do Território e Meio ambiente na Amazônia (GAPTA/CNPQ). E-mail: jmpalheta@ufpa.br \\ 2 Professor Associado III/Universidade Federal do Amapá/Líder do Grupo Dinâmicas Territoriais na Amazônia (DITAMA/CNPq). E-mail: \\ ricardoangelo_pereira@yahoo.es
}

\begin{abstract}
RESUMO: Este artigo analisa os territórios explorados pelos Grandes Projetos mineradores na Amazônia do sudeste paraense, especialmente os municípios de Marabá, Parauapebas e Canaã dos Carajás, durante os anos de 2004 a 2012, região Norte do Brasil, e os impactos territoriais que têm provocado alterações nos processos socioeconômicos de forma diferenciada e com complexidades particulares a cada um desses municípios, colocando em debate o papel da mineração como instrumento de ordenamento territorial e indicativo de desenvolvimento regional a partir da economia mineral, nas cidades sedes que abrigam Grandes empreendimentos de mineração.

Palavras-chave: Mineração. Território. Parauapebas. Canaã dos Carajás. Amazônia.
\end{abstract}

\begin{abstract}
This article analyzes the territories explored by the Large Mining Projects in the Amazon of the Southeast of Pará, especially the municipalities of Marabá, Parauapebas and Canaã dos Carajás, during the years 2004 to 2012, North region of Brazil, and the territorial impacts that have caused changes in socioeconomic processes in a differentiated way and with particularities in each of these municipalities, putting in debate the role of mining as an instrument of territorial planning and indicative of regional development from the mineral economy, in the host cities that host Large mining enterprises.
\end{abstract}

Keywords: Mining. Territory. Parauapebas. Canaã dos Carajás. Amazon.

Sumario: Introdução - 1 Cidades Mineradoras na Amazônia Paraense - 2 Conflitos Territoriais nos Municípios Mineradores - Considerações Finais - Referências

\section{INTRODUÇÃO}

Neste artigo será analisado mais detidamente os municípios de Marabá, Parauapebas e Canaã dos Carajás (figura 01), na região sudeste do estado do Pará, região Norte do Brasil e

\footnotetext{
${ }^{1}$ Ao longo da pesquisa, este autor recebeu apoio Financeiro da Fundação Amazônia de Amparo à Estudos e Pesquisas (FAPESPA) e da Coordenação de Aperfeiçoamento de Pessoal de Nível Superior (CAPES).
}

Planeta Amazônia: Revista Internacional de Direito Ambiental e Políticas Públicas 
os processos de ordenamento territorial causados pela globalização econômica, durante o período de 2004 a 2012, e a apropriação dos recursos minerais pelas empresas mineradoras e seus desdobramentos socioterritoriais, tentando mostrar que o território é um espaço sóciopolítico-econômico e que os exercícios de poder são relações que fazem desses municípios um território de complexidades variadas no tempo e no espaço, pelos diferentes atores sociais, como novas dinâmicas econômicas impulsionadoras de novas territorialidades e os conflitos sociosterritoriais nos municípios que sediam os principais projetos de mineração na região sudeste do estado do Pará.

Figura 01 - Área do Antigo Município de Marabá

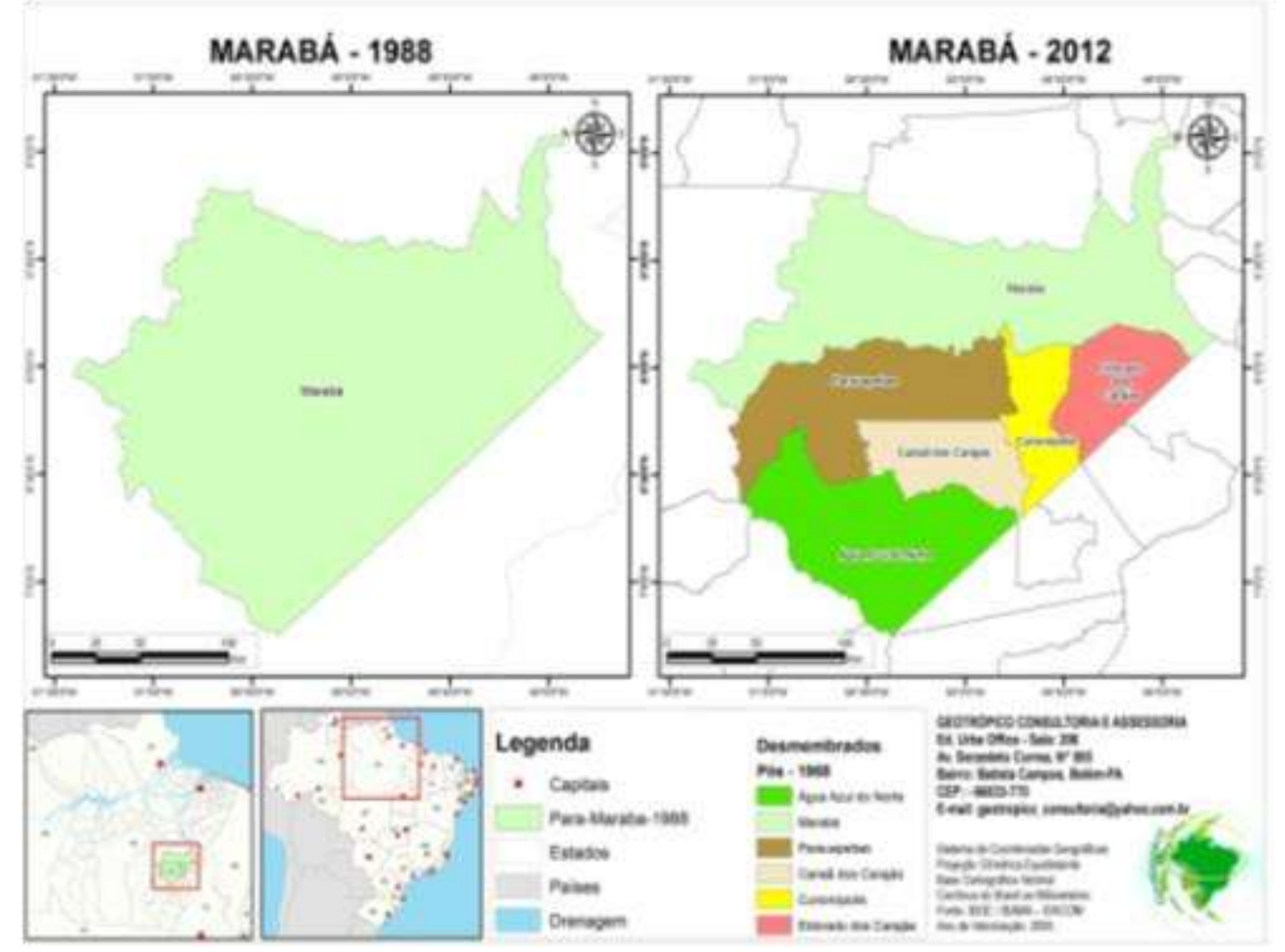

Fonte: Geotrópico Consultoria e assessoria (2017)

Com base em entrevistas e documentações que foram coletadas, in loco, junto a atores locais envolvidos nas formas de produção do espaço geográfico na região de Carajás, procurou-se analisar as relações de bases material e financeira do poder econômico dos grupos que controlam a mineração em escala internacional junto àquelas relacionadas ao poder social, investido nas elites locais e nos movimentos sociais diversos.

Há a definição de práticas e gestão territoriais de uma maneira peculiar, o que por sua vez expressa que, em determinados momentos, essas relações definem a configuração territorial que corresponde aos interesses relacionados tanto às empresas e ao Estado quanto às elites e aos movimentos sociais, na busca por seus interesses no Pará, no período de 2004 a 2012. 


\section{CIDADES MINERADORAS NA AMAZÔNIA PARAENSE:}

Segundo o Departamento Nacional de Produção Mineral (DNPM), no ranking dos dez municípios que mais geraram receitas de Compensação Financeira pela Exploração de Recursos Minerais (CFEM) no Brasil, nove municípios são podutores de minério de ferro, e Parauapebas (24\%) é o município com maior receita de CFEM, Canaã dos Carajás (1,8\%) é o décimo de toda a arrecadação nacional, os dez juntos respondem por $73 \%$ da CFEM referente ao segundo semestre de 2012 (DNPM/Informe Mineral, jul./dez. 2012).

Gráfico 01 - Exportação de Minério de Ferro do Estado do Pará

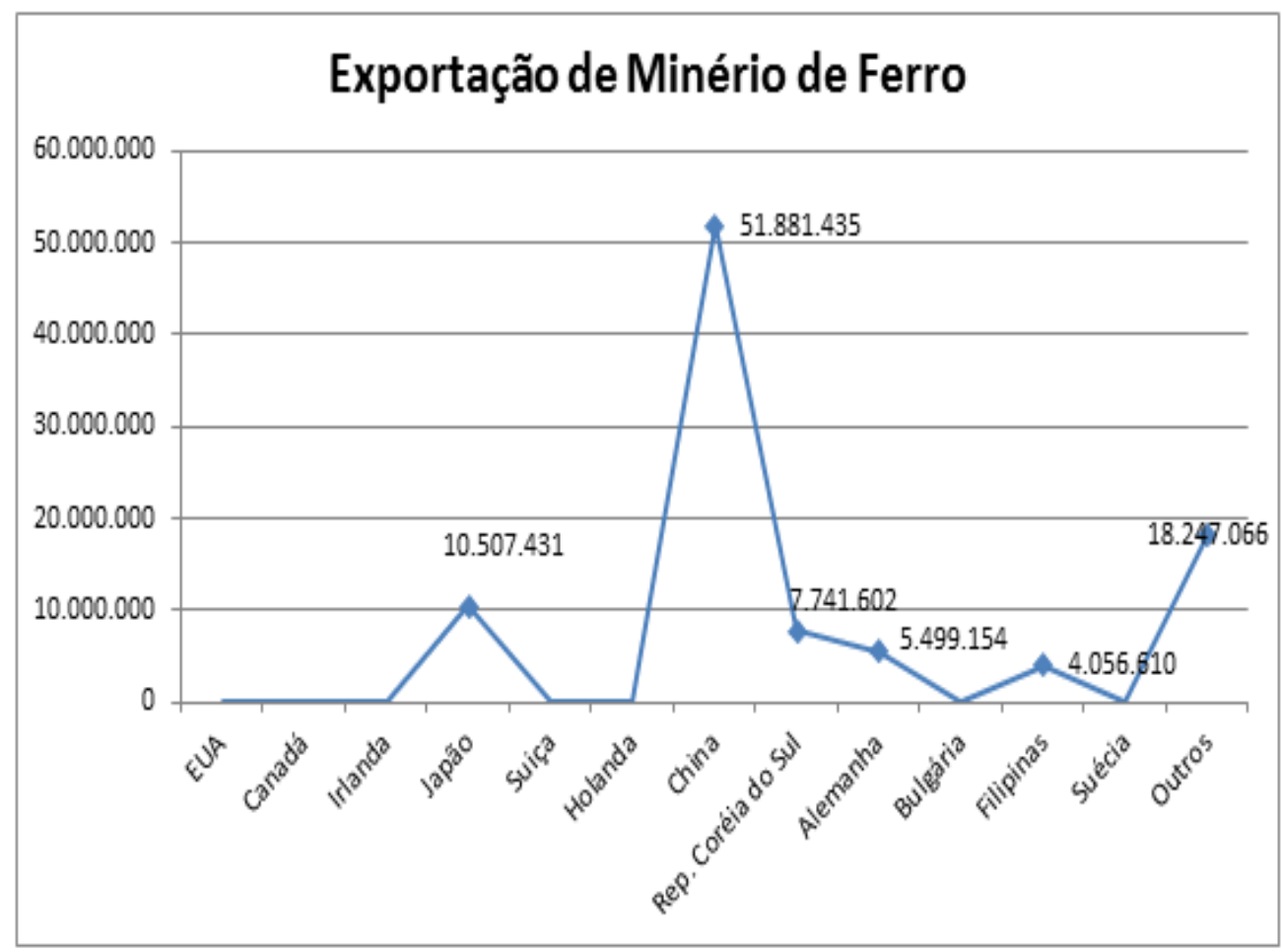

Fonte: . Adaptado de SIMINERAL, 2013.

Nesta perspectiva, não se pode deixar de notar que no estado do Pará dois municípios novos, criados da fragmentação do município de Marabá (figura 01), Parauapebas (minério de ferro), desmembrado, em 1988 e Canaã dos Carajás (minério de cobre), desmembrado em 1994, lideram a arrecadação e são responsáveis por grande parte da balança comercial do estado e conectam a economia paraense ao mundo (Gráficos 01 e 02). 
Gráfico 02 - Exportação de Cobre do Estado do Pará

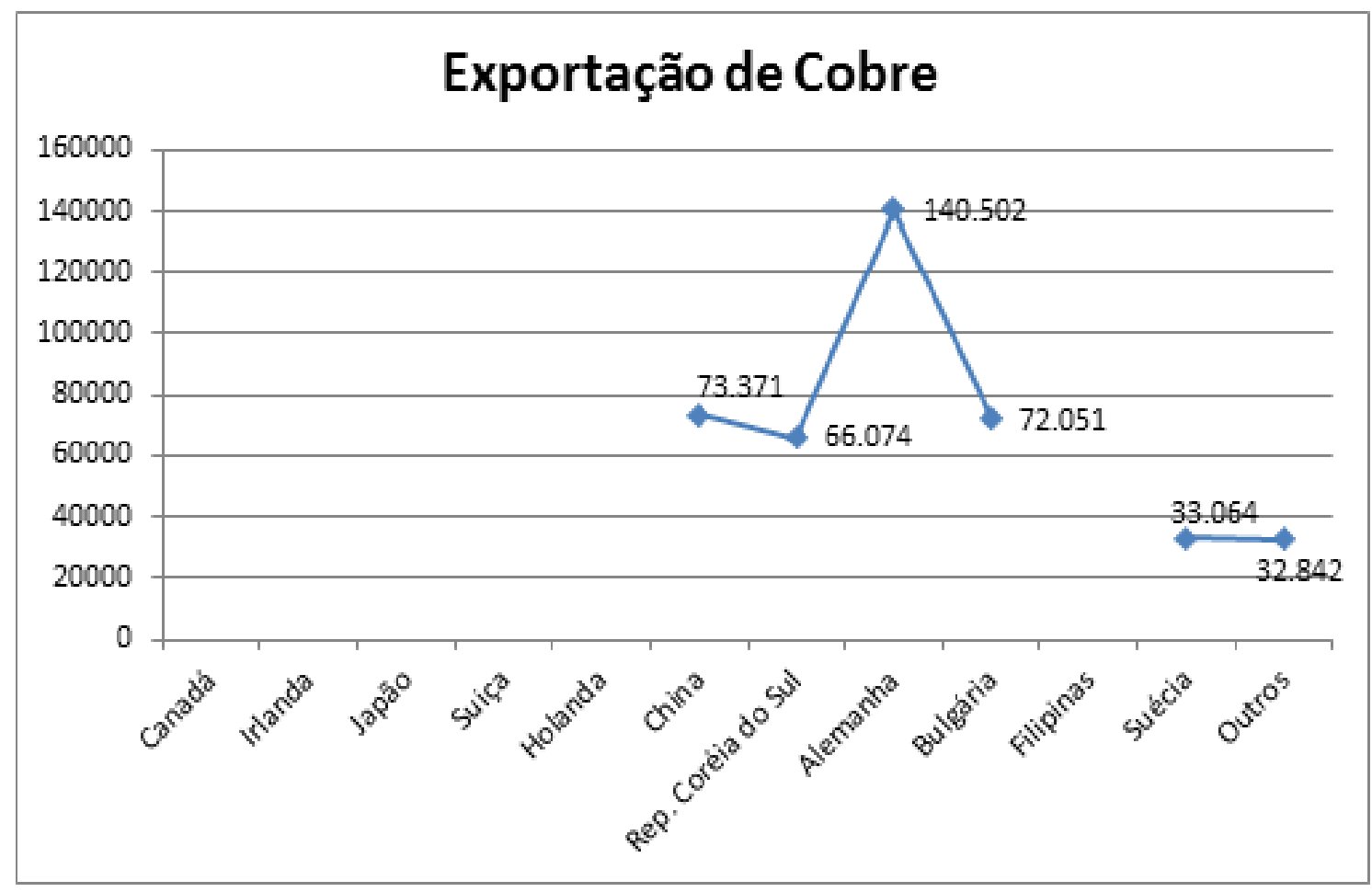

Fonte: .Adaptado de SIMINERAL, 2013.

Os municípios aqui estudados possuem suas arrecadações diferenciadas e dinâmicas econômicas próprias. Desde suas emancipações, municípios como Parauapebas e Canaã dos Carajás, enfrentam problemas comuns e com grau de capacidade de resolução diferenciado de acordo com sua potencialidade político-econômico-social para resolvê-los, sejam eles urbanos ou rurais, como destaca a tabela 01.

Tabela 01: Municípios Mineradores/Arrecadação de FPM no Pará no período de 2010 a 2012

\begin{tabular}{l|r|r|r}
\hline \multicolumn{1}{c|}{ Município } & \multicolumn{1}{c|}{$\mathbf{2 0 1 0}$} & \multicolumn{1}{c|}{$\mathbf{2 0 1 1}$} & \multicolumn{1}{c}{$\mathbf{2 0 1 2}$} \\
\hline Parauapebas & \multicolumn{1}{c|}{$38.549 .611,58$} & $46.222 .186,36$ & $48.528 .336,89$ \\
\hline Canaã dos Carajás & $7.502 .033,00$ & $9.035 .598,00$ & $9.205 .834,28$ \\
\hline Oriximiná & $11.788 .908,81$ & $15.489 .596,24$ & $15.781 .429,93$ \\
\hline Paragominas & $16.075 .784,62$ & $19.361 .995,25$ & $19.726 .787,43$ \\
\hline Juruti & $8.573 .751,99$ & $12.907 .996,96$ & $13.151 .191,72$ \\
\hline Ipixuna do Pará & $10.717 .189,79$ & $14.198 .796,58$ & $14.466 .310,90$ \\
\hline Marabá & $39.621 .330,59$ & $47.512 .985,93$ & $48.528 .336,89$ \\
\hline São Félix do Xingu & $18.071 .195,56$ & $12.860 .627,72$ & $19.726 .787,43$ \\
\hline Floresta do Araguaia & $5.358 .595,13$ & $7.744 .798,31$ & $7.890 .715,19$ \\
\hline Jacareacanga & $9.645 .470,84$ & $6.453 .998,61$ & $9.666 .225,43$ \\
\hline Total dos Dez Municípios & $\mathbf{1 6 5 . 9 0 3 . 8 7 1 , 9 1}$ & $\mathbf{1 9 1 . 7 8 8 . 5 7 9 , 9 6}$ & $\mathbf{2 0 6 . 6 7 1 . 9 5 6 , 0 9}$ \\
\hline Total do Estado & $\mathbf{1 . 5 6 7 . 3 9 6 . 0 2 5 , 9 2}$ & $\mathbf{1 . 9 3 1 . 5 3 1 . 1 9 0 , 0 6}$ & $\mathbf{2 . 0 1 3 . 8 7 8 . 4 1 7 , 7 8}$ \\
\hline
\end{tabular}

Fonte: http://migre.me/afP1V. (adaptado), 2016. 
Assim, o Imposto sobre Circulação de Mercadorias e Serviços (ICMS), o Fundo de Participação dos Municípios (FPM), o Imposto sobre Produto Industrializados (IPI) e os próprios royalties da Vale são soluções e esperança de crescimento econômico local. Acreditam os governos municipais que esses recursos são a "tábua de salvação" dos municípios que não conseguem atrair investimentos e têm, nesses repasses, seu grande "filão" para manter o discurso desenvolvimentista e continuar a garantir suas relações de poder no território e a manutenção de seus governos.

No caso de Parauapebas são mais de 400 milhões de reais, quando somados os dois tributos juntos (Tabelas 01 e 02). Em seguida vem Canaã dos Carajás - município emancipado em razão da mineração - posteriormente Oriximiná, Paragominas e Juruti, municípios mais antigos e que não surgiram em função da atividade mineral. A mineração é a principal atividade nos dois primeiros municípios, mas todos estão ligados à economia internacional, pela atuação em seus territórios de grupos mineradores de exploração em alta escala, como o Grupo Vale.

Tabela 02: Principais Municípios Arrecadadores da CFEM no Estado do Pará no período de 2010 a 2012

\begin{tabular}{l|r|c|r}
\hline \multicolumn{1}{c|}{ Município } & \multicolumn{1}{c|}{$\mathbf{2 0 1 0}$} & Município & \multicolumn{1}{c}{$\mathbf{2 0 1 1}$} \\
\hline Parauapebas & \multicolumn{1}{c}{$229.896 .598,41$} & Parauapebas & $371.088 .416,69$ \\
\hline Canaã dos Carajás & $26.389 .306,77$ & Canaã dos Carajás & $31.953 .067,54$ \\
\hline Oriximiná & $18.598 .141,94$ & Oriximiná & $21.220 .281,78$ \\
\hline Paragominas & $10.916 .670,65$ & Paragominas & $12.336 .831,69$ \\
\hline Juruti & $12.297 .592,13$ & Juruti & $10.717 .061,23$ \\
\hline Ipixuna do Pará & $8.140 .172,26$ & Ipixuna do Pará & $7.114 .356,53$ \\
\hline Marabá & $6.083 .211,67$ & São Félix do Xingu & $2.709 .765,44$ \\
\hline Floresta do Araguaia & $1.081 .809,74$ & Floresta do Araguaia & $1.970 .968,68$ \\
\hline Itaituba & $318.755,37$ & Marabá & $1.874 .832,81$ \\
\hline Jacareacanga & $32.293 .979,65$ & Itaituba & $306.528,09$ \\
\hline Total dos Dez Municípios & $314.845 .129,95$ & & $461.292 .110,48$ \\
\hline Total do Estado & $\mathbf{3 4 6 . 0 1 6 . 2 3 8 , 5 9}$ & & $\mathbf{4 6 2 . 4 0 8 . 8 0 8 , 0 4}$ \\
\hline
\end{tabular}

Fonte: http://migre.me/afOZp. (adaptado pelos autores), 2016.

O repasse de ICMS entre os anos de 2004 e 2012 tem na amostragem da Tabela 3, uma definição de quanto cada um dos dois municípios do Sudeste Paraense têm arrecadado nesses últimos anos. Esses repasses têm oscilado ao longo dos anos analisados. Nos municípios como Marabá, Parauapebas e Canaã dos Carajás, pode-se fazer uma análise mais detalhada dos anos e verificar a evolução da arrecadação do ICMS.

Em outros municípios, como Água Azul do Norte, Curionópolis e Eldorado dos Carajás esse crescimento é tímido. Por essa razão, em alguns momentos suas arrecadações crescem quando comparadas com as de municípios mais antigos, como é o caso de Marabá e com os mais recentes e economicamente dinâmicos com a mineração presentes em seus territórios, como é o caso Parauapebas e Canaã dos Carajás. 
Tabela 03 - ICMS dos dois Municípios Estudados da Mesorregião Sudeste Paraense 2004 - 2012

\begin{tabular}{r|r|r|r}
\hline Ano & Canaã dos Carajás & Parauapebas & \multicolumn{1}{c}{ Total/Estado/ano } \\
\hline $\mathbf{2 0 0 4}$ & $1.331 .357,42$ & $52.998 .266,85$ & $512.060 .549,36$ \\
\hline $\mathbf{2 0 0 5}$ & $1.939 .888,83$ & $60.682 .147,46$ & $606.215 .259,31$ \\
\hline $\mathbf{2 0 0 6}$ & $4.765 .582,79$ & $66.227 .584,35$ & $700.820 .998,44$ \\
\hline $\mathbf{2 0 0 7}$ & $11.691 .129,29$ & $71.216 .552,25$ & $764.126 .097,16$ \\
\hline $\mathbf{2 0 0 8}$ & $15.307 .511,55$ & $76.622 .599,48$ & $850.417 .308,34$ \\
\hline $\mathbf{2 0 0 9}$ & $19.325 .959,46$ & $87.828 .773,53$ & $907.322 .040,60$ \\
\hline $\mathbf{2 0 1 0}$ & $19.630 .849,92$ & $119.224 .010,00$ & $1.027 .793 .189,63$ \\
\hline $\mathbf{2 0 1 1}$ & $21.371 .427,70$ & $147.771 .422,51$ & $1.142 .857 .095,95$ \\
\hline $\mathbf{2 0 1 2}$ & $26.442 .158,75$ & $226.919 .716,37$ & $1.412 .949 .666,07$ \\
\hline Total & $\mathbf{1 2 5 . 9 0 4 . 6 9 4 , 8 7}$ & $\mathbf{1 . 0 8 8 . 9 9 4 . 4 4 4 , 4 5}$ & $10.207 .306 .236,99$ \\
\hline
\end{tabular}

Fonte: http://www.sefa.pa.gov.br/site/pagina/tesouro.repasse.

Nesse conjunto de repasses de ICMS para os seis municípios da mesorregião Sudeste Paraense, cada um tem sua participação em relação aos repasses realizados nos períodos de 2004 a 2012. De acordo com sua posição em cada período, Parauapebas é o primeiro município em arrecadação de ICMS, seguido de Marabá e Canaã dos Carajás como os maiores arrecadadores; enquanto municípios como Água Azul do Norte, Curionópolis e Eldorado dos Carajás seguem entre aqueles que menos arrecadam.

As transferências de receitas são depositadas no FPM, no ICMS e no IPI, basicamente. Dessa forma pode-se constatar que o aumento gradativo dessas transferências tem esbarrado na boa ou má administração municipal. Assim, elas beneficiam municípios como Marabá, Parauapebas e Canaã dos Carajás e contribuem com as parcerias e com outros tributos, como os royalties, para aumentar a arrecadação municipal. No caso dos municípios como Eldorado dos Carajás, Curionópolis e Água Azul do Norte essas transferências são essenciais, porque esses municípios dependem diretamente desses recursos para viabilizar a gestão territorial local.

Parauapebas, segundo lugar, Marabá, quarta posição e Canaã dos Carajás, oitavo lugar estão entre os maiores PIB dos municípios paraenses (Tabela 4). Essa classificação demonstra o peso de Marabá e Parauapebas dentro do Pará e dentro da mesorregião, assim como de Canaã dos Carajás, Barcarena, Tucuruí e Paragominas, municípios que possuem em seus territórios grandes projetos e que são municípios política e economicamente importante no Pará. No ranking nacional dos 100 maiores municípios brasileiros, em relação ao PIB, em 2010, Belém ocupava a 27ạ posição e Parauapebas a 33ạ, no valor a preços correntes e participações percentuais relativas acumuladas (Contas Nacionais na 39/IBGE, 2010).

Tabela 04: Repasse de IPI aos Municípios 2004 - 2012

\begin{tabular}{c|c|r|r|r|r}
\hline Municípios & \multicolumn{1}{|c|}{$\mathbf{2 0 0 4}$} & \multicolumn{1}{c|}{$\mathbf{2 0 0 6}$} & \multicolumn{1}{c|}{$\mathbf{2 0 0 8}$} & \multicolumn{1}{|c|}{$\mathbf{2 0 1 0}$} & $\mathbf{2 0 1 2}$ \\
\hline Canaã dos Carajás & $24.035,63$ & $117.340,71$ & $640.136,03$ & $760.533,91$ & $1.010 .825,15$ \\
\hline Parauapebas & $956.802,82$ & $2.366 .033,32$ & $3.204 .236,45$ & $4.618 .949,38$ & $8.681 .204,23$ \\
\hline Total do estado do Pará & $9.244 .471,68$ & $24.254 .065,59$ & $35.563 .112,66$ & $39.818 .529,15$ & $54.048 .817,40$ \\
\hline
\end{tabular}

Fonte: http://www.sefa.pa.gov.br/site/pagina/tesouro.repasse. 
No que diz respeito ao PIB (Tabela 5) dos municípios estudados, destacam-se Parauapebas, Marabá e Canaã dos Carajás, em relação aos demais municípios paraenses. Dentre os 10 maiores PIB do estado do Pará, em 2010, estão a capital Belém em primeiro lugar, seguida de Parauapebas, Ananindeua, Marabá, Barcarena, Santarém, Canaã dos Carajás, Castanhal e Paragominas.

Tabela 05: PIB dos dez Principais Arrecadadores do Estado do Pará - 2010

\begin{tabular}{c|l|l|l|l}
\hline \multicolumn{1}{c|}{ Ranking } & \multicolumn{1}{|c|}{ Município } & \multicolumn{1}{c|}{ PIB (R\$) } & Participação & Setor predominante \\
\hline $\mathbf{1}$ & Belém & 17.987 .323 & 23,11 & Serviços \\
\hline $\mathbf{2}$ & Parauapebas & 15.918 .216 & 20,45 & Indústria \\
\hline $\mathbf{3}$ & Ananindeua & 3.6669 .747 & 4,71 & Serviços \\
\hline $\mathbf{4}$ & Marabá & 3.601 .647 & 4,63 & Serviços \\
\hline $\mathbf{5}$ & Barcarena & 3.550 .233 & 4,56 & Indústria \\
\hline $\mathbf{6}$ & Tucuruí & 2.817 .702 & 3,62 & Indústria \\
\hline $\mathbf{7}$ & Santarém & 2.051 .529 & 2,64 & Serviços \\
\hline $\mathbf{8}$ & Canaã dos Carajás & 1.1 .559 .968 & 2,00 & Indústria \\
\hline $\mathbf{9}$ & Castanhal & 1.449 .213 & 1,86 & Serviços \\
\hline $\mathbf{1 0}$ & Paragominas & 1.235 .379 & 1,59 & Indústria \\
\hline Total Municípios & Total municípios & 53.840 .957 & 69,15 & Serviços/ \\
\hline Total Estado do Pará & & 77.847 .597 & 100 & Indústria \\
\hline
\end{tabular}

Fonte: Dados básicos: IBGE e IPEA, apud, SILVA, 2013.

Dentro dessa análise, dos municípios que foram desmembrados de Marabá (serviços) apenas Parauapebas e Canaã dos Carajás (indústria) demonstram viabilidade econômicofinanceira (Tabela 6), devido à presença da Vale e os projetos a ela associados, como também aos diversos assentamentos rurais existentes em seus territórios, como é o caso dos assentamentos do Movimento dos Sem Terra (MST) na região. Esses assentamentos, de certa forma contribuem na base produtiva dos municípios e impulsionam, em momentos de crise, o comércio local.

Tabela 06 - Estrutura Produtiva Municipal por Participação (\%) da Área Estudada

\begin{tabular}{l|l|l|l|l}
\hline Municípios & Agropecuária & Indústria & Serviços & Predominância \\
\hline Água Azul do Norte & $33,0 \%$ & $30,5 \%$ & $35,6 \%$ & Serviços \\
\hline Canaã Carajás do & $2,1 \%$ & $83,7 \%$ & $14,2 \%$ & Indústria \\
\hline Curionópolis & $33,5 \%$ & $8,9 \%$ & $57,8 \%$ & Serviços \\
\hline Eldorado dos Carajás & $19,6 \%$ & $31,8 \%$ & $48,7 \%$ & Serviços \\
\hline Marabá & $2,5 \%$ & $33,0 \%$ & $64,5 \%$ & Serviços \\
\hline Parauapebas & $0,2 \%$ & $87,5 \%$ & $12,2 \%$ & Indústria
\end{tabular}

Fonte: IDESP/IBGE - Adaptado pelos autores - Produto Interno Bruto Municipal, 2010. apud, SILVA, 2013.

No aspecto da mobilidade existe, a respeito do FPM (tabela 7), uma relação direta entre aqueles municípios que não possuem atividades econômicas atrativas para as empresas de mineração como a Vale. Nesse caso, o FPM é uma das principais fontes financeiras para o município e essa análise pode ser feita desde 1997. 
Tabela 07 - Repasse do Fundo de Participação aos dois Municípios do Estado do Pará entre os anos de 1997-2012

\begin{tabular}{r|r|r|r}
\hline \multicolumn{1}{c|}{ Ano } & Canaã dos Carajás & \multicolumn{1}{c|}{ Parauapebas } & \multicolumn{1}{c}{ Total/Estado/ano } \\
\hline $\mathbf{1 9 9 7}$ & $\mathbf{7 8 2 . 9 7 4 , 1 1}$ & $1.826 .939,31$ & $349.511 .100,79$ \\
\hline $\mathbf{1 9 9 8}$ & $1.081 .295,42$ & $2.162 .590,44$ & $376.310 .942,12$ \\
\hline $\mathbf{1 9 9 9}$ & $1.250 .800,45$ & $2.501 .600,31$ & $414.276 .296,19$ \\
\hline $\mathbf{2 0 0 0}$ & $1.411 .276,29$ & $2.822 .552,13$ & $464.358 .529,46$ \\
\hline $\mathbf{2 0 0 1}$ & $1.810 .835,21$ & $5.213 .208,52$ & $544.613 .700,68$ \\
\hline $\mathbf{2 0 0 2}$ & $1.962 .202,13$ & $6.377 .155,79$ & $673.617 .646,55$ \\
\hline $\mathbf{2 0 0 3}$ & $2.045 .119,96$ & $6.646 .638,39$ & $698.101 .380,79$ \\
\hline $\mathbf{2 0 0 4}$ & $2.258 .725,97$ & $7.340 .857,92$ & $773.753 .233,84$ \\
\hline $\mathbf{2 0 0 5}$ & $2.790 .842,32$ & $9.761 .633,83$ & $970.051 .876,14$ \\
\hline $\mathbf{2 0 0 6}$ & $3.085 .952,73$ & $10.798 .634,68$ & $1.070 .364 .647,35$ \\
\hline $\mathbf{2 0 0 7}$ & $4.412 .616,55$ & $13.238 .442,14$ & $1.227 .440 .628,58$ \\
\hline $\mathbf{2 0 0 8}$ & $6.478 .101,17$ & $19.434 .302,72$ & $1.525 .620 .728,63$ \\
\hline $\mathbf{2 0 0 9}$ & $7.032 .924,18$ & $36.245 .596,41$ & $1.453 .107 .720,43$ \\
\hline $\mathbf{2 0 1 0}$ & $7.502 .033,00$ & $38.549 .611,58$ & $1.567 .396 .025,92$ \\
\hline $\mathbf{2 0 1 1}$ & $9.035 .598,00$ & $46.222 .186,36$ & $1.931 .531 .190,06$ \\
\hline $\mathbf{2 0 1 2}$ & $9.205 .834,28$ & $48.528 .336,89$ & $2.013 .878 .417,78$ \\
\hline Total 16 anos & $\mathbf{6 2 . 1 4 7 . 1 3 1 , 7 7}$ & $\mathbf{2 5 7 . 6 7 0 . 2 8 7 , 4 2}$ & $\mathbf{1 6 . 0 5 3 . 9 3 4 . 0 6 5 , 3 1}$ \\
\hline
\end{tabular}

Fonte: Ministério da Fazenda - Secretaria do Tesouro Nacional 2013.

http://www3.tesouro.fazenda.gov.br/estados_municipios/transferencias_constitucionais.asp.

Para outros, que possuem projetos definidos pela Vale, e que recebem os royalties da mineração, o FPM é um elemento a mais na sua arrecadação (Nesse caso os novos municípios Parauapebas e Canaã dos Carajás não dependem diretamente das transferências dos impostos). Assim, o local (município) é a escala que melhor expressa essas trilhas financeiras, que equivalem às relações de poder nas disputas tanto entre os municípios quanto entre os atores político-econômicos locais e extra locais.

É nessa perspectiva que se pode entender a integração das atividades mineradoras presentes em municípios como Marabá, Parauapebas e Canaã dos Carajás e a possível virtualidade de outros projetos em Curionópolis e Água Azul do Norte, por exemplo. Nessa ótica, não só o Estado, mas também as empresas e os diferentes atores econômicos utilizaram-se dos recursos financeiros, tornando-os elementos pelos quais os discursos do poder local mobilizam a sociedade para tentar garantir seu domínio municipal.

\section{CONFLITOS TERRITORIAIS NOS MUNICÍPIOS MINERADORES}

O município de Parauapebas, emancipado em 1988, por sediar a Vale e a infraestrutura montada pelo Projeto Ferro Carajás (PFC), apresenta condições de expansão e desenvolvimento singulares em relação aos outros municípios. A influência direta da Companhia Vale no seu começo, com a formação do núcleo urbano de Parauapebas para abrigar funcionários que iriam trabalhar na implantação do PFC e, posteriormente, dos royalties foram fatores fundamentais para sua emancipação. Este município continua a ser dinamicamente influenci- 
ado pela atuação local dessa companhia.

As relações político-econômicas do município sofrem influência direta e indireta da Vale, o que por um lado favoreceu a conjuntura sócio-político-econômica do município. A sociedade civil em Parauapebas cresceu e traçou seus projetos em função das possibilidades que a companhia trazia para o município em torno de investimentos.

A relação de poder nesse município foi alterada, na medida em que o município crescia e novos atores sociais ascendiam ou tentavam ascender ao poder. O município cresceu em população e em problemas sociais também, o que por sua vez favoreceu ainda mais os discursos políticos locais em virtude da captação de recursos para se resolverem os problemas que estavam surgindo.

Um dos representantes desses novos atores sociais, a Associação Comercial e Industrial de Parauapebas (ACIP), é a entidade de representação de empresários locais. Segundo seu vice-presidente (2003), essa representação estava crescendo. O mesmo argumentava que, embora a associação estivesse se fortalecendo, a atividade industrial dependia do desenvolvimento das atividades da Vale, a principal empresa. O desenvolvimento do comércio dependia dos trabalhos gerados direta e indiretamente pela Vale, das empreiteiras que prestavam serviços à companhia e do crescimento populacional do município.

Quando ocorre a expansão local da Vale, o comércio melhora suas vendas; mas se há desmontagem de algum projeto ou finda uma obra, acontece a retração das atividades comerciais, às vezes até o chamado "calote" acontece, por parte de empregados de empreiteiras que terminando os serviços, migram para outras localidades e com elas os empregos que estavam sendo gerados no município. Assim, há uma diminuição no volume de negócios e de dinheiro circulando pela cidade.

As questões referentes aos investimentos sofrem críticas de alguns empresários, associações e sindicatos que estão fora do poder público. Segundo alguns entrevistados, o que o município arrecada não tem se traduzido em investimentos que tenham beneficiado a sociedade como um todo, seja no setor urbano, seja no rural.

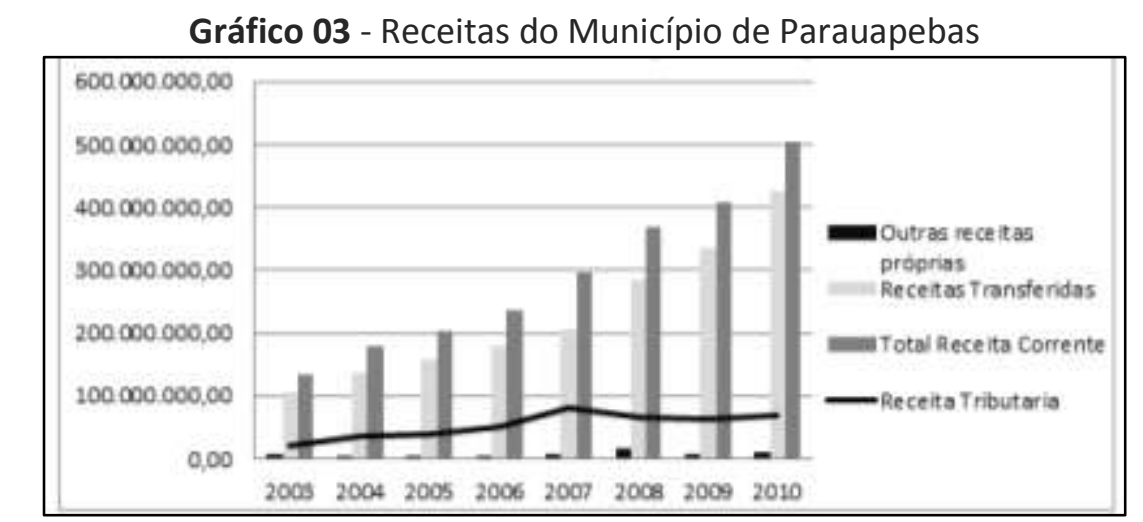

Fonte: http://www.sefa.pa.gov.br. https://www.tesouro.fazenda.gov.br/

Outra questão inibidora é a forte e contínua migração para o município. Estudos realizados na segunda metade da década de 1990, a pedido da Vale, acusaram que para cada em- 
prego gerado, outras sete ou oito pessoas migrariam para a cidade. Dessa forma, esse número considerável de desempregados acabou aumentando o contingente de pessoas nos movimentos sociais rurais e a parte urbana do município.

Fatores como esses fazem Parauapebas ter uma realidade interessante: verdadeiros bairros são formados com migração de outros estados como Maranhão, por exemplo, facilitada pela Estrada de Ferro Carajás (EFC), e de outros municípios como Curionópolis. Com isso os problemas sociais também se agravam.

A maneira como se tem tratado as imigrações e os problemas gerados por elas, bem como por projetos que a Vale poderá implantar, como os que foram implantados em Parauapebas e municípios vizinhos, é um desafio para a gestão municipal e para toda a sociedade civil organizada. De uma forma ou de outra, será necessário fazer com que a presença da Vale seja importante nessas discussões. O que não se pode é colocar a empresa fora dos problemas gerados, porque não é só o benefício em forma de receita que interessa ao município, mas o que realmente se poderá fazer em função da presença de um grande projeto de mineração, que acelerou as transformações territoriais deste município.

Outro questionamento feito, em 2003, referia-se à posição do METABASE, cujo principal foco é a terceirização que, segundo membros do sindicato, tem prejudicado a representatividade e impedido o aumento do número de associados. Pois a mão-de-obra vinda com empresas rotativas de outros estados, como Minas Gerais, chegam já sindicalizadas. Essa rotatividade de empresas que vêm prestar serviços para a Vale, segundo o METABASE, tem imobilizado o sindicato.

As críticas contra ou a favor da presença da companhia, e das formas de desenvolvimento encontradas pelo poder público em Parauapebas, são relacionadas a um conjunto de múltiplos fatores que envolvem diferentes interesses e são determinantes na forma como o município vem realizando a gestão territorial.

O município de Canaã dos Carajás foi desmembrado de Parauapebas em 1991, surgido do antigo CEDERE II ${ }^{2}$. Em 2003, viveu um período único de sua história, cercado de loteamentos realizados na época do CEDERE. O seu núcleo residencial presenciou uma metamorfose catastrófica, uma ebulição populacional, gente vindo de todas as partes do Sul e Sudeste paraense e do Nordeste brasileiro, principalmente do Maranhão, em função da implantação do Projeto Mineração Serra do Sossego da Vale, que começou a explorar o cobre ${ }^{3}$ no ano de 2004, e que está em fase de operação no município.

O Projeto Mineração Serra do Sossego, sem dúvida, transformou Canaã dos Carajás em um território de atração populacional, município que teve seu objetivo inicial que era de Centro de Desenvolvimento Regional (CEDERE II) com base agrícola, e que mudou recentemente para economia extrativa mineral. Com isso, as atividades da Vale mudam a função dos muni-

\footnotetext{
${ }^{2}$ Centro de Desenvolvimento Regional criado pelo GETAT na década de 1980.

${ }^{3}$ Segundo o Informe Mineral do DNPM "A produção de cobre vem declinando paulatinamente a cada ano, tornando-se insuficiente ao atendimento interno, configurando, assim, uma dependência externa de $80 \%$. Em relação ao ano anterior, a produção de concentrado, em termos de metal contido, situou-se abaixo de 9,5\%. Essa desaceleração constatada é fruto da paralisação e encerramento das atividades da mina a céu aberto da Mineração Caraíba S/A, ocorrida em setembro de 1998" (DNPM, 2000, p. 08).
} 
cípios que estão sob sua área direta de atuação.

Mesmo com o PDS, não havia como evitar a migração. Antes mesmo de entrar em operação, o projeto atraiu muita gente e a localidade virou um canteiro de obras, com pessoas vindas de todos os lugares da região e do Maranhão. Com isso, aumentaram os problemas sociais dos municípios, que como Canaã, não possuíam condições de absorver toda essa população.

Num ponto as administrações municipais estão de acordo: as migrações acabam ficando na periferia da cidade e em condições também precárias, contribuindo para o inchaço urbano e para a formação de enormes bairros problemáticos, como os bairros Liberdade e Maranhão, em Parauapebas.

Nesse caso, os investimentos que a Vale realizou, em parceria com a prefeitura, não conseguiram evitar a desordem urbana, nem a vinda de mais migrantes para cidade. É comum encontrar migrantes perambulando pelas ruas do município, atraídos pelo Projeto Mineração Serra do Sossego, que como muitos projetos da Vale, geraram investimentos no município e trouxeram junto com eles graves problemas sociais.

As migrações eram controladas; dentro da área dos CEDERES. O GETAT se encarregava de disciplinar a distribuição dos lotes. E, com os técnicos agrícolas que foram enviados para ficar na área somente seis meses, viabilizando as técnicas para facilitar a produção do CEDERE II, o projeto logo começou a apresentar problemas. Havia também outros interesses, um deles é que os centros deveriam servir de abastecimento para os trabalhadores da Vale, cujos produtos teriam a própria empresa como consumidora.

Porém, somente o CEDERE II conseguiu certo sucesso na fixação do trabalhador no campo. E com as dificuldades que foram surgindo, nem o próprio CEDERE II conseguiu sustentar todos que para ali migraram. Acabaram por vender seus lotes a terceiros e, aos poucos, os mais capitalizados foram formando grandes fazendas. Ainda mais com a saída dos técnicos agrícolas depois do término do contrato.

A situação piorou, na visão de um antigo morador, quando o GETAT abandonou o projeto. As dificuldades aumentaram, o CEDERE II ficou quase que isolado do resto da região, o que fez com que muitos dos antigos moradores vendessem seus lotes e migrassem para Marabá, Parauapebas e outras localidades. Por conta disso a pecuária foi tomando cada vez mais espaço na região do CEDERE II. Dessa forma, este projeto foi ficando esquecido como centro de abastecimento agrícola para as localidades próximas como Parauapebas, e como as estradas ficaram ruins o tempo de duração do percurso entre o CEDERE II e Parauapebas aumentou, dificultando ainda mais a vida dos colonos.

No começo do projeto, em 2003, ocorreu uma confusão por causa da infraestrutura que estava sendo montada, não se encontrava mais nada no lugar. As casas e o comércio iam se formando em função da via principal; prédios estavam sendo construídos da noite para o dia; hotéis surgiram para abrigar os trabalhadores do MSS, muitos dos quais dormiam (ou ainda dormem) em Parauapebas, onde a maioria dos hotéis estava reservada para as empresas que estão trabalhando no Sossego.

A crítica de um antigo morador recai na falta de posicionamento do poder local. Ele a- 
credita que o projeto que foi construído na cidade possui visão somente da Vale. E por não possuir a visão do cidadão de Canaã, tal projeto fere os interesses e os costumes locais. Quem estava acostumado com um estilo de vida, com uma forma de viver e pensar a cidade sabe que o tempo da cidade mudou por fatores econômicos, que inseriram o município na economia do cobre e modificaram sua relação com o lugar, com as pessoas que passaram a viver em função do projeto ou da expectativa que ele pode dar a cada um dos que vivem ali. Pessoas que estão vendo reconstruírem sua cidade sem pedirem sua opinião, sem consultar seus anseios.

A crítica feita por um antigo morador recai na falta de posicionamento do poder local, uma vez que na construção do projeto a população não teria sido consultada, e que só foi levada em consideração a visão da empresa. Com isso, o projeto não atendeu aos interesses e os costumes do lugar.

Por outro lado, ele depositava toda sua esperança nos recursos que viriam com a implantação do projeto. Depois de 2004 começariam a pagar os royalties da mineração e com isso a receita municipal aumentaria (Gráfico 4). Era nisso que quase todos os municípios apostavam e pleiteavam nos projetos da Vale, esperando que os recursos que a companhia iria repassá-los, serviriam como elementos de investimentos no local e se tornasse um indicador de desenvolvimento.

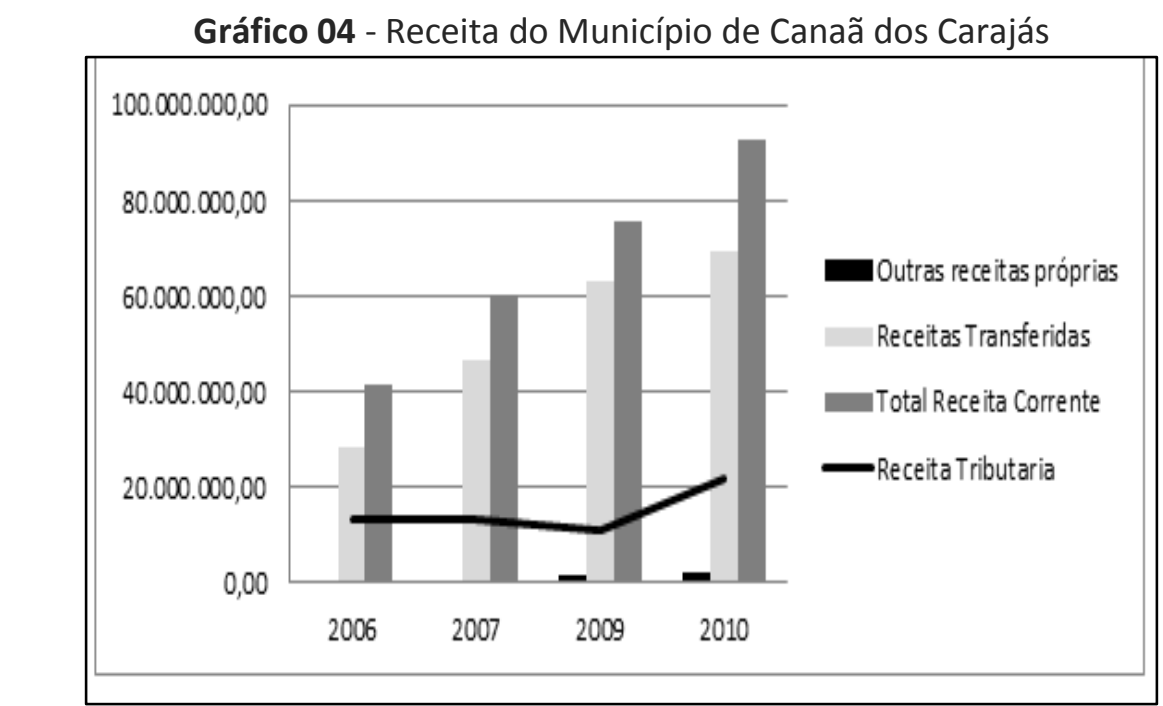

Fonte:http://www.sefa.pa.gov.br.https://www.tesouro.fazenda.gov.br/. Não estavam disponibilizados no site os dados dos anos de 2003 a 2005.

Por uma razão ou outra, o poder público não estava interessado nos elementos adversos que surgiriam com a instalação do Projeto Cobre, problemas urbanos e rurais, e sim na viabilização financeira, no aumento das receitas, sem se preocupar se tais atividades poderão gerar prejuízo aos municípios. Assim, não se preocupam com a sustentabilidade social do município e com o desenvolvimento das condições socioeconômicas do mesmo. Somente concentram suas atenções no aumento de receita que esses projetos poderão atrair para a sede municipal. 
A expectativa agora é para o maior projeto da Vale na região, que está dentro do município de Canaã dos Carajás, o Projeto Ferro Carajás S11D ${ }^{4}$, que divide duas áreas, a de influência direta que abrange os municípios de Canaã dos Carajás e Parauapebas e, a outra, a área considerada de influência indireta pela companhia que abrange mais 24 municípios.

Ainda segundo informações do site da Vale a empresa recebeu autorização para iniciar as obras do ramal ferroviário que ligará a mina de S11D em Canaã dos Carajás à Estrada de Ferro Carajás, aumentando assim, sua capacidade logística no sistema norte.

\section{CONSIDERAÇÕES FINAIS}

Parauapebas e Canaã dos Carajás são ainda municípios novos, em termos de emancipação política e econômica. Esses municípios apresentam antigos problemas sociais agravados com a introdução da mineração e por planejamentos realizados sem a participação da sociedade civil ou de grupos que disputam o poder local. Em relação à questão econômicofinanceira, a maioria dos municípios da mesorregião Sudeste Paraense são pobres, com pequena arrecadação, dependem do repasse do governo federal e têm sua receita atrelada ao FPM.

São municípios que têm total dependência financeira, que acabam onerando outros municípios por não possuírem infraestrutura suficiente para atender sua população, que busca serviços melhores em outra localidade próxima, também acabam migrando para municípios como Parauapebas, Canaã dos Carajás ou para Marabá, os três mais bem estruturados, entre os seis municípios estudados.

Estes terminam recebendo problemas que deveriam ser resolvidos nos municípios adjacentes. As prefeituras acabam sendo o principal empregador, e sem perspectivas de atrair indústrias e serviços, esses municípios entregam seu futuro em termos de desenvolvimento econômico às vontades dos projetos que poderiam ser implantados por parte da companhia Vale.

Outro destaque está relacionado à dependência que os municípios têm em torno das atividades de mineração da Vale, que monopoliza a exploração dos minérios na região. Nas entrevistas, foi quase que unânime a questão da necessidade de abertura do Sul e Sudeste Paraense para que outras empresas realizarem suas prospecções.

Outras companhias precisam dividir com a Vale a responsabilidade econômica e social pelo desenvolvimento dos projetos na região. Acredita-se que só assim haverá uma redistribuição de poder econômico em virtude da quebra do monopólio exercido pela empresa na região. Parauapebas e Canaã dos Carajás, são municípios que possuem projetos de mineração e acabam se destacando dentro de microrregiões, por possuírem as atividades principais da

\footnotetext{
${ }^{4}$ Segundo o RIMA sobre o projeto, o "S11D abrange 24 municípios do Sudeste Paraense que possuem estreitas vinculações territoriais, econômicas e sociais com os municípios de Canaã dos Carajás e Parauapebas, que serão diretamente impactados pelo empreendimento. Área de Influência Indireta de acordo com o número de habitantes. Percebe-se que os municípios que são Pólos regionais como Marabá, Parauapebas, São Félix do Xingu e Xinguara apresentam as maiores populações. Já Canaã dos Carajás, município no qual se pretende instalar o empreendimento, ocupa uma posição intermediária, no 10 lugar, à frente de outros 14 municípios". (Rima Projeto Ferro Carajás S11D, 2012. p 93).
}

Planeta Amazônia: Revista Internacional de Direito Ambiental e Políticas Públicas 
Vale na região.

Os questionamentos feitos em alguns municípios, dentre eles Parauapebas, é sobre a vida útil de cada projeto que a Vale tem na região. Em alguns casos, como Canaã dos Carajás, o projeto tem vida curta. Talvez por isso a indiferença de um representante do poder público municipal, que já alertava sobre as possíveis migrações que viriam daquele município em direção a Parauapebas aumentando os problemas sociais do Município.

As discussões sobre o aumento da alíquota têm que ser acompanhadas por um novo jeito de pensar o desenvolvimento na região, que leve em consideração a sociedade local e os impactos gerados por esses projetos. É preciso não repetir os mesmos erros do passado, não apenas na quantificação, mas na qualificação da aplicação desses recursos, não permitindo que as empresas montem totalmente suas infraestruturas fora do estado, ficando este somente como fornecedor da matéria prima.

\section{REFERÊNCIAS}

DEPARTAMENTO NACIONAL DE PRODUÇÃO MINERAL. Informe Mineral, jul./dez. 2012. <http://www.anm.gov.br/dnpm/informes/informe-mineral-2012-2o-semestre>. Acessado em 06 de março de 2017.

GOVERNO DO PARÁ. ICMS dos Municípios Estudados da Mesorregião Sudeste Paraense 1997 - 2012. <http://www.sefa.pa.gov.br/site/pagina/tesouro.repasse>. Acessado em 07 de março de 2017

http://www.ibge.gov.br

http://www.sefa.pa.gov.br.

https://www.tesouro.fazenda.gov.br

MINISTÉRIO DA FAZENDA. Secretaria do Tesouro Nacional 2013. <http://www3.tesou ro.fazenda.gov.br/estados_municipios/transferencias_constitucionais.asp> Acessado em 06 de março de 2017.

PALHETA DA SILVA, João Marcio. Território e Mineração em Carajás. Belém: GAPTA/UFPA. 2013.

SIDICATO DAS INDUSTRIAS MINERAIS DO ESTADO DO PARÁ. Anuário da Mineral do Pará. Belém: SIMINERAL, 2013.

VALE. A Vale em Parauapebas. Paraupebas: Vale, Relatório, 2014. <http://www.vale.com/pt/ aboutvale/sustainability/links/linksdownloadsdocuments/relatorio-vale-parauapebas-

2014.pdf>. Acessado em 24 de julho de 2016.

VALE. Projeto Ferro Carajás S11D. Um novo impulso ao desenvolvimento sustentável do Brasil. Vale, 2012.

VALE. RIMA do Projeto Ferro Carajás S11D. Paraupebas: Vale, 2012.

Artigo recebido em 16 de abril de 2018.

Aprovado em 24 de abril de 2018. 